\title{
Advanced Thermopile IR Dual Line Sensor for Smart Home
}

\author{
Christophe Escriba, Julien Roux, Georges Soto-Romero, Pascal Acco, David Bourrier, \\ Eric Campo, Jean-Yves Fourniols
}

LAAS-CNRS, Université de Toulouse, CNRS, INSA, UT2J, Toulouse, France

Email: cescriba@laas.fr

How to cite this paper: Escriba, C., Roux, J., Soto-Romero, G., Acco, P., Bourrier, D., Campo, E. and Fourniols, J.-Y. (2018) Advanced Thermopile IR Dual Line Sensor for Smart Home. Journal of Sensor Technolo$g y, 8,69-87$.

https://doi.org/10.4236/jst.2018.84006

Received: July 16, 2018

Accepted: November 16, 2018

Published: November 19, 2018

Copyright $\odot 2018$ by authors and Scientific Research Publishing Inc. This work is licensed under the Creative Commons Attribution International License (CC BY 4.0).

http://creativecommons.org/licenses/by/4.0/

\begin{abstract}
This article presents all steps between the advanced design and the production of CMOS compatible thermoelectric effect infrared sensors dedicated to smart home applications. It will start by making a comparison between thermopile, bolometer and pyroelectric technologies. Although sensitivity performances available with bolometers appear to be better at first sight, it is found that thermopiles have non-negligible advantages that make them more suitable for this application field. Then the different steps necessary for the design will be described, starting from the thermoelectric model of the sensor (temperature gradient, electrical sensitivity, etc.) and considering all steps up to technological manufacturing in a clean room. The results obtained on the structures produced on a specific computer-controlled measurement bench (temperature regulation with an onboard preamplification card) will be presented. Finally, the results prove that the square structures have better performances $(\mathrm{S}=82 \mathrm{~V} / \mathrm{W}$ and $\mathrm{NETD}=208 \mathrm{mK})$.
\end{abstract}

\section{Keywords}

Thermopile Array, Thermoelectric Model, Three-Dimensional

Micro-Machining, Self-Regulated Special-Purpose Measurement Bench

\section{Introduction}

Progress in micro technologies now makes it possible to combine monolithic integration of new multifunction detectors with massive collective production to give good reliability. This technological progress, including particularly the application of micro-machining techniques and deposition of CMOS compatible thin layers, accounts for a large share of the economic stakes involved in low cost components for both military and civil applications. In the field of smart home 
application, user safety and comfort functions must necessarily be based on definite detection of presence of a person. Our proposed solution is based on an uncooled system running at ambient temperature $(300 \mathrm{~K})$ and adapted to the 7 $14 \mu \mathrm{m}$ spectral band. These detectors firstly need to be sensitive to the types of photons emitted, but must also be capable of discerning small radiation differences centered about an average value in a high ambient background level. Thus, we will justify the choice of this technology in this study. The scientific community usually mentions pyroelectric effects [1], thermoelectric effects [2], [3] bolometric effects [4] and also thermomechanical effects [5] as electrical phenomena involved in the measurement of IR thermal flux. Their common operating principle is based on the resultant of a temperature rise of the detector under the action of incident infrared radiation that modifies the physical properties of a chosen material after it has been absorbed. Usually the IR sensor arrays consist of one membrane by pixel [6], [7]. In this paper we present an original technology that permits obtaining a dual line sensor in one-off membrane for all pixels. We will restrict ourselves to a comparison of the thermopile and bolometric technologies in Section 2.

We then present the thermoelectric model necessary to evaluate and to theoretically size fundamental parameters of the sensor in Section 3. We will then describe the different technological steps essential to the production of sensors in Section 4, and Section 5 presents the specific characterization bench that we made so as to evaluate the performances of the different structures produced. Finally, we conclude this work by presenting the results obtained from the sensors as a function of their topology.

\section{Advantages of the Thermopile Compared with the Pyroelectric and Bolometric Detection in a Smart Home Application}

The detection capacity of pyroelectric sensors derived from the uncooled detectors line is differentiated from other sensors because it is restricted to detecting the dynamic behavior of a person rather than his intrinsic static presence. In other words, if there is no mechanical action to generate flux variations, the sensor can detect if a person is present and moving, but can never detect a person who is not moving. As a result, technologies making use of bolometric and thermoelectric detectors potentially offer the best solutions for satisfying new requirements, particularly for the static detection of persons. Table 1 summarizes the advantages and disadvantages of each technology so that we can study them and make a selection

The information in the Table 1 are extracted from publications about microbolometer and thermopile sensors [8]-[13]. At first sight, the microbolometric sensor appears to be an attractive choice. Compared with the thermopile, its detectivity is higher; it has a high performance NETD and a significantly better response time. Obviously, these qualities are necessary, but they may not be sufficient. The specificity of the system to be designed is such that, above all, it must 
Table 1. Summary and comparison of characteristics: microbolometric/thermopile sensors.

\begin{tabular}{|c|c|c|}
\hline Sensor type & Microbolometer & Thermopile \\
\hline Category & Passive (resistance) & Active (voltage generator) \\
\hline $\begin{array}{l}\text { Electrical sensitivity } \\
\qquad\left(\mathrm{V} \cdot \mathrm{W}^{-1}\right)\end{array}$ & $\begin{array}{c}5 \times 10^{3} \text { to } 10^{6} \\
\text { (after amplification) }\end{array}$ & $\begin{array}{c}6 \text { to } 120 \\
\text { (before amplification) }\end{array}$ \\
\hline Specific detectivity $\left(\mathrm{W}^{-1} \cdot \mathrm{cm} \cdot \mathrm{Hz}^{1 / 2}\right)$ & $10^{8}$ to $10^{9}$ & $10^{6}$ to $10^{8}$ \\
\hline NETD $(\mathrm{mK})$ & $\begin{array}{c}\quad<<230 \\
\text { (after amplification) }\end{array}$ & $\begin{array}{c}<400 \\
\text { (after amplification) }\end{array}$ \\
\hline Response time (ms) & 15 to 20 & 15 to 65 \\
\hline Source of noise & $1 / \mathrm{f}$ and thermal & Thermal \\
\hline Linear response & No & Yes \\
\hline $\begin{array}{l}\text { Need to input a bias circuit } \\
\text { (before amplification) }\end{array}$ & $\begin{array}{l}\text { Yes (Wheatstone bridge, } \\
\text { current mirror, etc.) }\end{array}$ & No (Self generator) \\
\hline Self-heating & Yes (bias current) & No \\
\hline $\begin{array}{l}\text { Need to regulate the focal plane } \\
\text { starting from the Peltier module }\end{array}$ & Yes & No \\
\hline Operation in a vacuum & $\begin{array}{l}\text { Yes (duration not more } \\
\text { than ten (10) years) }\end{array}$ & No \\
\hline Imagery cost $(\mathrm{k} €)$ & อ อ อ (5 to 20$)$ & $\ddot{\bullet}$ \\
\hline
\end{tabular}

enable static detection of an IR flux, in addition to dynamic detection. In other words, it is essential to minimize the influence of low frequency noise sources, particularly noise in $1 / f$ that is present in the resistance of bolometers due to bias currents effect. Furthermore, due to these bias currents, the bolometer is influenced by a self-heating phenomenon that causes a drift in the sensitivity [8] [9]. This is why the bolometer is kept at a reference temperature obtained from a Peltier effect cooling module, causing an increase in the global energy consumption of the system. Finally, note that one constraint on this type of system, namely the cost, makes it impossible to vacuum seal the sensor. But microbolometers do operate under a vacuum [10] [11].

Consequently, we believe that it would be better to use thermopile sensors for the development of a home automation detection system. This type of sensor does not need a bias circuit, because, due to its intrinsic nature, it converts an IR illumination into an e.m $f$. directly without the need for any external electrical energy source, which will eventually be beneficial. It is then no longer useful to use a system to regulate the focal plane of the sensor. Concerning noise, it is found that the detectivity of this type of sensor is only affected by thermal noise, and $1 / f$ noise is practically non-existent [12] [13]. The response time is longer than the response time of bolometers but is not prejudicial for the design of a presence detection system. A priori, only the sensitivity could be critical in terms of feasibility. One possible means of overcoming this would be to develop a high gain voltage amplifier between $80 \mathrm{~dB}$ and $120 \mathrm{~dB}$. Moreover, firstly a thermopile 
does not need a vacuum environment to operate, and also its voltage response is perfectly linear, unlike microbolometric sensors that usually require the addition of a linearization circuit.

This is why, due to the maturity of silicon microsystems, prospects for collective production and low manufacturing costs, we have decided to design, make and characterize different thermopile topologies for the development of a presence detector within the LAAS-CNRS laboratory.

\section{Single Pixel Thermoelectric Model}

We thought it was important to model the thermopile first so as to obtain the best possible size for the adapted structure. The typical topology of the detector is shown in Figure 1, based on the association of thermojunctions connected in series to increase the output voltage. The thermoelectric properties of conducting materials cause the appearance of a potential difference due to the effect of differential temperature rise $(\mathrm{K})$ between the two thermojunctions, where denotes the Seebeck voltage [14] [15]. This self-generated voltage is defined as a function of the total number $\mathrm{N}$ of thermocouples and their corresponding Seebeck coefficient $\alpha_{1}, \alpha_{2}$.

$$
\Delta V=N\left(\alpha_{1}-\alpha_{2}\right)\left(T_{h}-T_{c}\right)=N \alpha_{12} R_{t h} \eta P_{0}
$$

In Equation (1), $R_{t h}(\mathrm{~K} / \mathrm{W})$ represents the thermal resistance of the thermopile, $\eta$ represents the absorption coefficient and $P_{0}$ the radiative power $(\mathrm{W})$ collected by the absorbent surface area of the sensor $S_{a}\left(\mathrm{~m}^{2}\right)$. The ratio of the generated voltage $\Delta V$ and the received power $P_{0}$ represents the electrical sensitivity of the thermopile, denoted $\mathfrak{R}_{v},\left(\mathfrak{R}_{v}=\Delta V / P_{0}=N \alpha_{12} R_{t h} \eta\right)$.

Taking account of the symmetry properties of the structure, we modeled the entire sensor analytically along the $x$ direction and we calculated the thermal gradient $\Delta T$ between the ends of the thermojunctions using the Fourier stationary heat equations Equation (2) considering the thermal conduction flows in the materials, and the heat fluxes exchanged by convection and radiation.
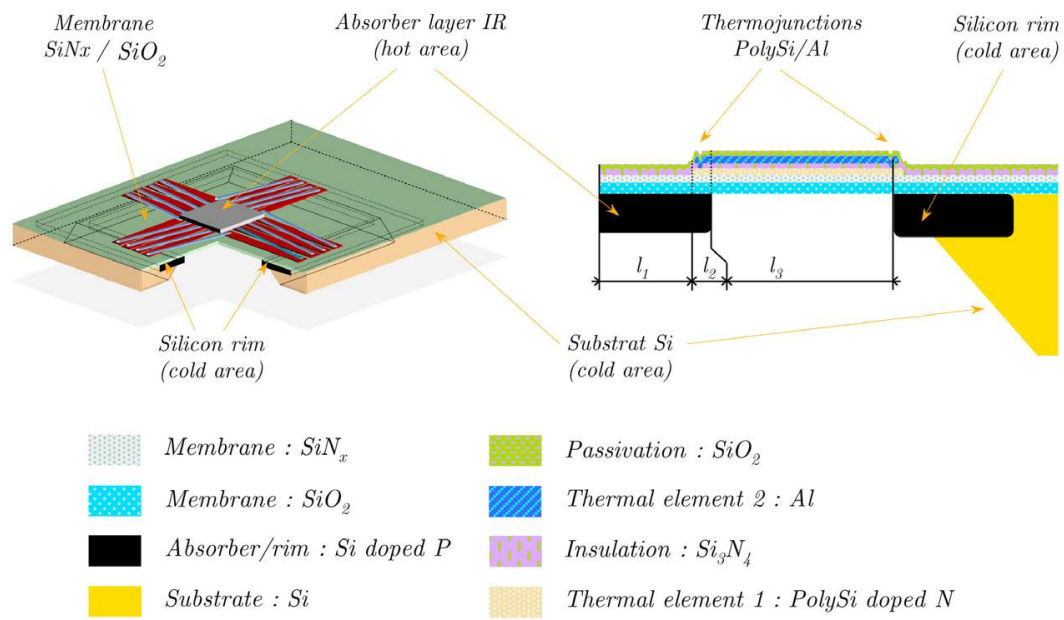

Figure 1. Thermopile basic structure. 


$$
-\lambda d \frac{\partial^{2} T(x)}{\partial x^{2}}+h\left(T(x)-T_{a}\right)+\sigma_{b} \varepsilon\left(T^{4}(x)-T_{a}^{4}\right)=\eta \Phi_{0}
$$

where $\lambda$ is the thermal conductivity, $d$ is the material thickness, $h$ is the coefficient of convection, $\sigma_{b}$ is the Stefan-Boltzmann constant, $\varepsilon$ is the coefficient of emissivity and $T(x)$ is the temperature along the element $\partial x$.

The temperature gradient between the hot and cold thermojunctions was determined by separating the global structure into 3 zones. We solved the heat transfer equation as a function of boundary conditions at the boundary of each of zone, respecting temperature continuity and conduction fluxes. Thus, the expression obtained for the temperature gradient $\Delta T$ between $T_{c}$ and $T_{h}$ is presented in Equation (3), in which the coefficients $A_{2}, \xi_{12}, \psi_{23}$ represent the total losses of heat exchanges per unit area and conduction flux shape factors [16], respectively.

$$
\Delta T=\frac{\eta \Phi_{0}}{A_{2}}\left(1+\frac{\xi_{12}}{\lambda_{2} k_{2}} \operatorname{coth}\left(k_{2} l_{2}\right)-\frac{\psi_{23}}{\lambda_{2} k_{2} \operatorname{sh}\left(k_{2} l_{2}\right)}\right)
$$

The electrical sensitivity $\mathfrak{R}_{v}$ is written as follows [16]:

$$
\Re_{v}=\frac{\left(\alpha_{1}-\alpha_{2}\right) N \eta}{A_{2} S_{a}}\left(1+\frac{\xi_{12}}{\lambda_{2} k_{2}} \operatorname{coth}\left(k_{2} l_{2}\right)-\frac{\psi_{23}}{\lambda_{2} k_{2} \operatorname{sh}\left(k_{2} l_{2}\right)}\right)
$$

The model that we developed takes account of the influence of the size of the absorber, the membrane and the thermocouples. We performed a detailed study [16] [17] [18] [19] [20] to evaluate the thermal behavior of the sensor and optimize its size. The model demonstrated that a compromise was necessary between the length of the thermocouples $\left(l_{2}+l_{3}\right)$ and the size of the absorber $W_{a}=$ $2\left(I_{1}+I_{2}\right)$ and that there is no point in oversizing the absorber. Although the Figure 2 shows that the temperature gradient increases when the size of the absorber increases, it also shows that this reduces the sensitivity of the sensor (Figure 3). Oversizing the absorber reduces the total thermal resistance of the thermopile.

\section{Manufacturing of Micromachined Dual Line Thermopile Sensor and Package Assembly}

The figures of the technology process (Figure 4) consist of a cross section of the thermopile array, crossing the device in the middle of the pixels.

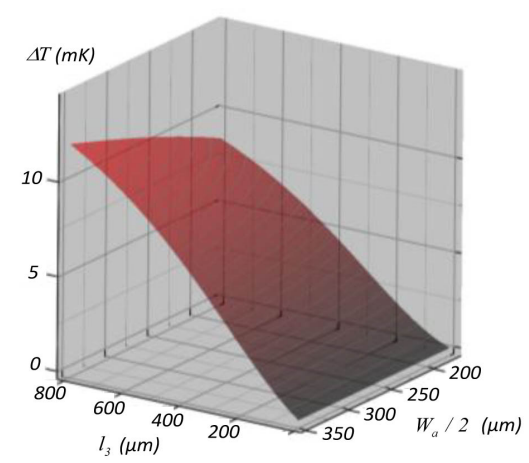

Figure 2. Temperature gradient between thermojunctions as a function of $l_{1}$ and $W_{a} / 2$. 


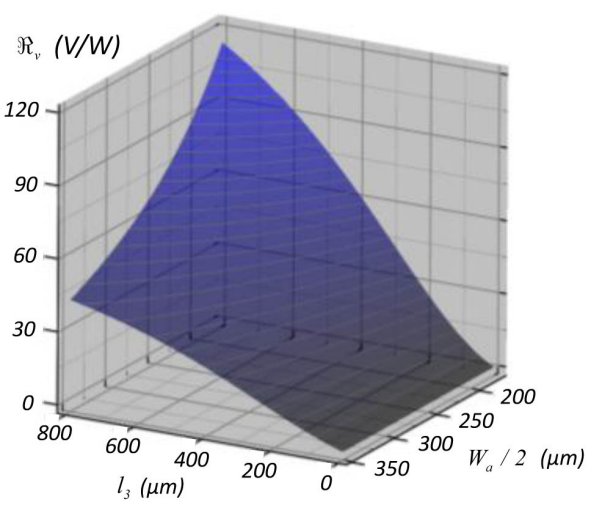

Figure 3. Sensitivity of the sensor as a function of $l_{1}$ and $W_{a} / 2$.

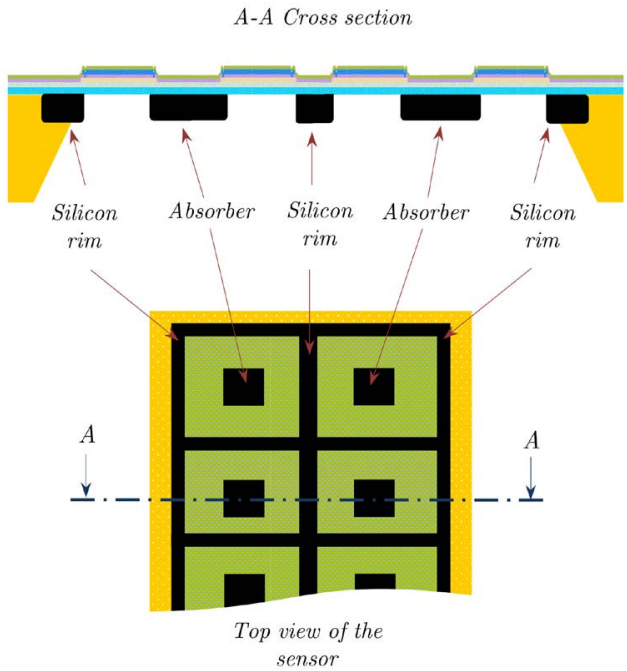

Figure 4. Dual line thermopile sensor.

The silicon rim showed between pixels is connected to the silicon bulk to insure the cold junction reference at the edge of the membrane. This approach is applied to our dual line sensor (thermopile array: $2 \times 8$ ).

The initial substrate on which all technological steps of the thermopile are based has the following characteristics: diameter 4", crystalline orientation $<100>$, material type N, $4-40 \Omega \cdot \mathrm{cm}^{-1}$, thickness $300 \mu \mathrm{m}$ with polished faces. Note that the manufacturing procedure is independent of the geometrical shape of the structures to be made (square, rectangular, etc.). We made the absorber after a first step dedicated to making alignment patterns etched in silicon by DRIE (Figure 5). We did this by doping a strong concentration of boron using a solid source doping process. This boron layer is located at the center of the sensor to enable conversion of IR radiation into heat necessary for operation of the thermopile. We positioned the absorber area under the membrane because the high concentration of boron carriers becomes effective stop-layers during the chemical etching [21] of silicon when the membrane is released. Figure 6 shows the SIMS doping profiles on which we measured a concentration of $1-1.5 \times 10^{20}$ $\mathrm{cm}^{-3}$ carriers over a depth of about $3-5 \mu \mathrm{m}$. 


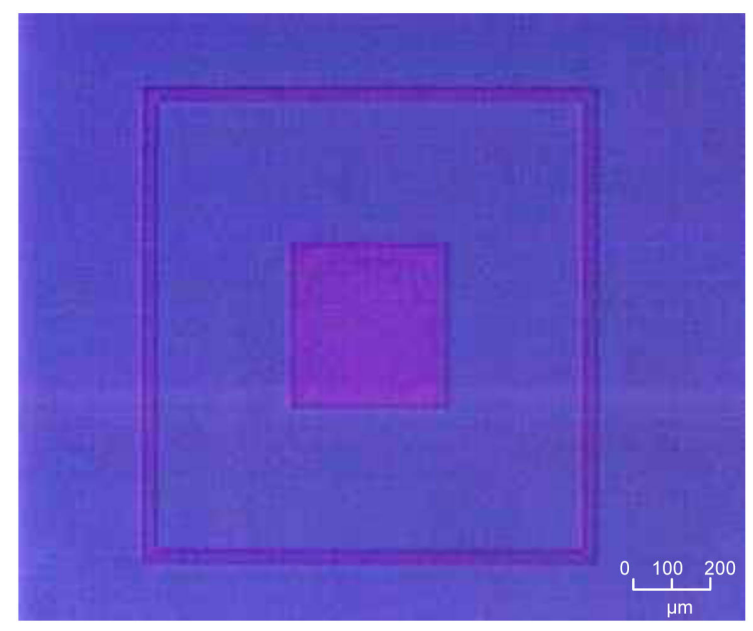

Figure 5. Microscopic photograph of the absorber location.

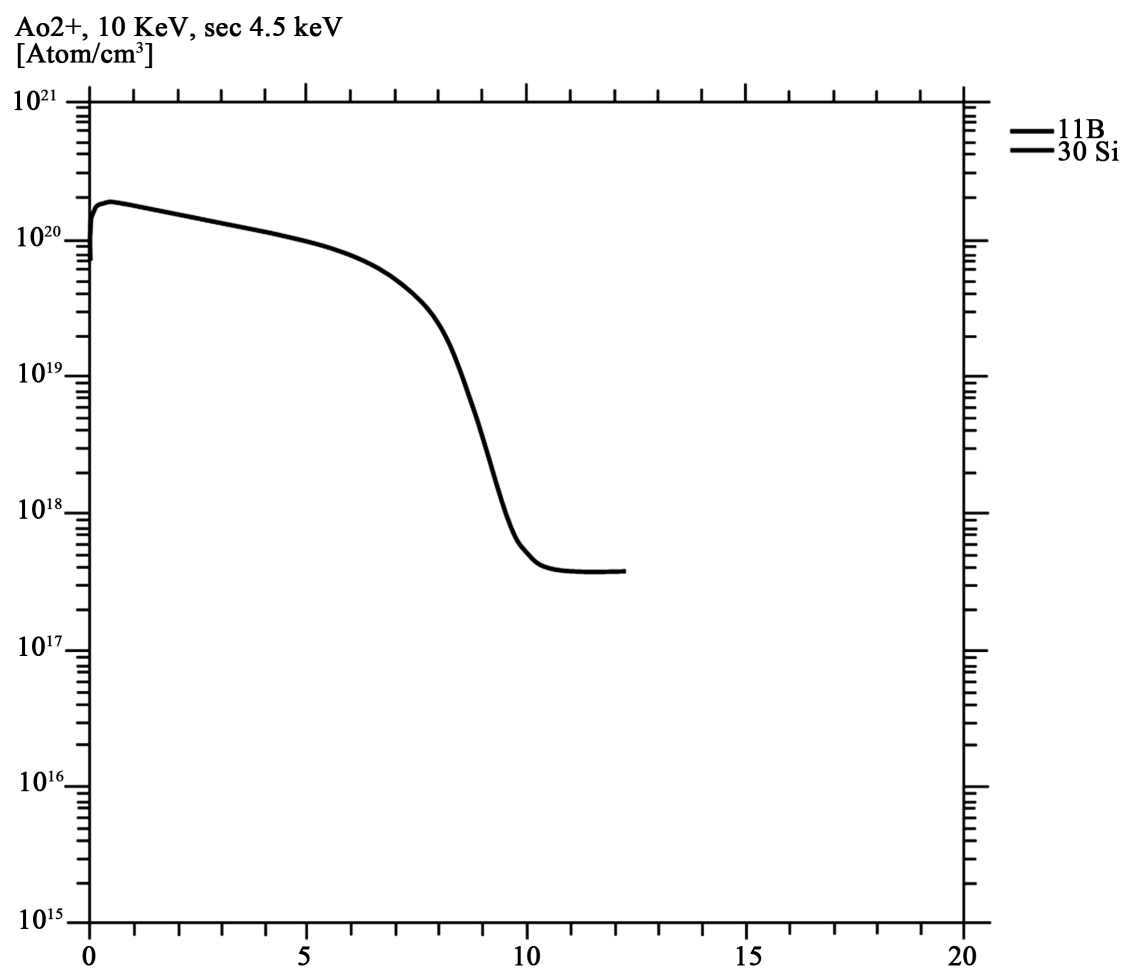

Figure 6. Distribution of the concentration of boron carriers in the silicon.

The next step after eliminating the masking oxide necessary for boron implantation is to deposit layers of $\mathrm{SiO}_{2}$ and $\mathrm{SiN}_{\mathrm{x}}$ essential for making the future membrane [22]. The step necessary for formation of the silicon oxide layer is done by a thermal oxidation. The nitride layer is obtained by low pressure chemical vapor phase deposition of Silane $\mathrm{SiH}_{4}$ and $\mathrm{NH}_{3}$ (LPCVD horizontal reactor). Their combination compensates to an average tensile stress of less than $50 \mathrm{MPa}$ for a total thickness of the double layer less than $1.5 \mu \mathrm{m}$ [23] [24]. In this case, the pair of thermoelectric materials (type N Polysilicon/aluminum) is deposited using conventional photolithographic processes isolated by an oxide and 
connected together at their corresponding ends. The thin layer of polycrystalline silicon is deposited by LPCVD and is doped in situ with phosphorus $\mathrm{POCl}_{3}$. A DRIE: ICP etching is done after this step (Figure 7) for the geometry of the PolySi arms. The electrical insulation layer is produced from a PECVD deposit, and a DRIE etching is then done for the oxide opening necessary for the electrical contact (Figure 8).

The aluminum arms are made by vacuum sputtering using the lift-off technique to obtain better resolution of the arms. A final PECVD oxide layer is deposited on the surface of the substrate to complete passivation of the thermopiles. A final photolithography step is necessary before the membrane is released by chemical etching of silicon, to define the dimensions of the membrane by locally eliminating the $\mathrm{SiO}_{2} / \mathrm{SiN}_{\mathrm{x}}$ double layer located on the lower face of the wafer by dry etching (DRIE:GIR). Finally, we did an anisotropic KOH chemical etching of the silicon substrate necessary to release the membrane [25] (Figure 9). Chips are connected by wedge bonding of small section aluminum wires (25 $\mu \mathrm{m})$. Figure 10 shows the structure mounted on its base and the cap fitted with its 7 - $14 \mu \mathrm{m}$ IR filter.

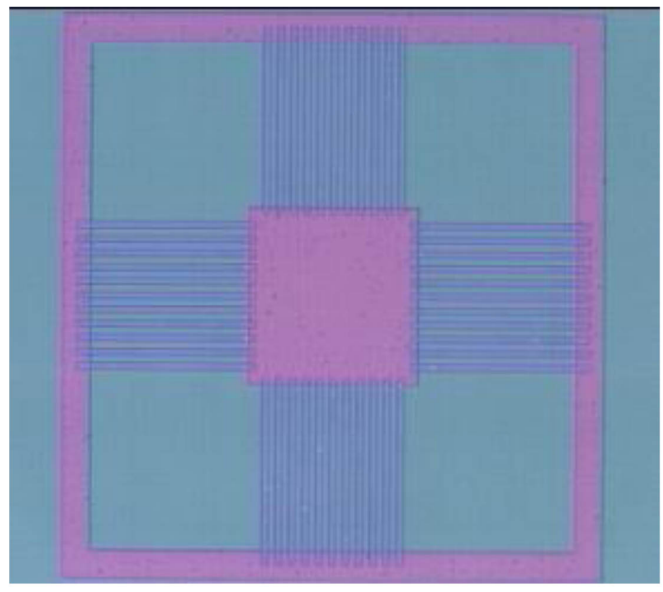

Figure 7. PolySi arms with the oxide layer necessary for electrical insulation of thermocouples.

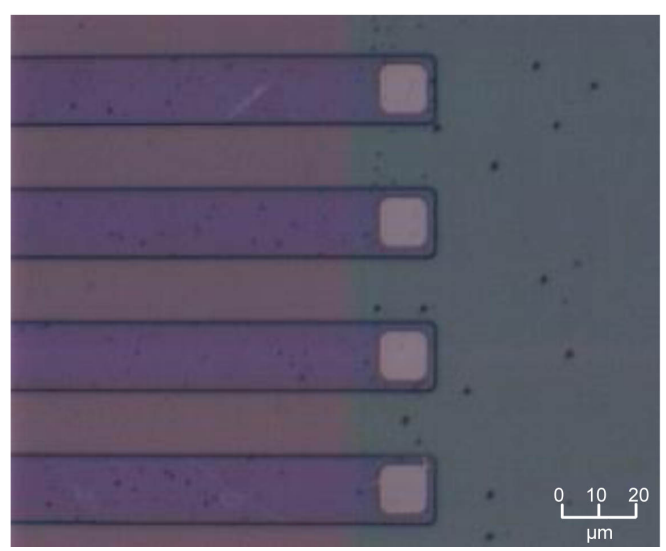

Figure 8. Oxide opening for electrical contacts. 


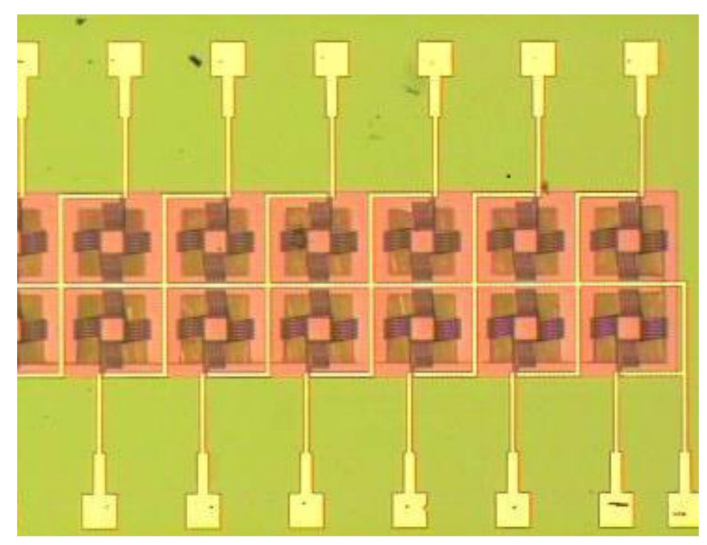

Figure 9. Finished dual line thermopile.

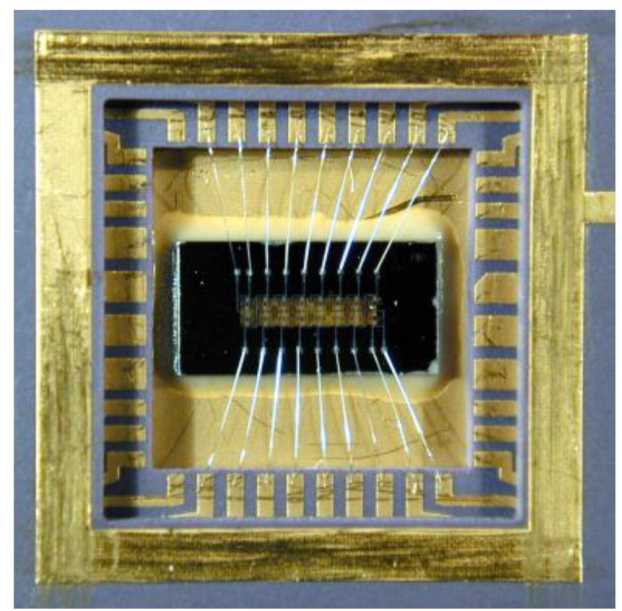

Figure 10. Thermopile mounted on its base with wired chip.

\section{Characterization of Thermopiles}

\subsection{Design and Manufacturing of a Specific Measurement Bench}

We designed a specific measurement bench dedicated to thermopiles in order to evaluate the sensitivity to an infrared flow, temperature drifts and NETD. An observation of the general variation of the output voltage of the sensors using this bench also enabled us to obtain the voltage variation equation as a function of the ambient temperature. The block diagram for the measurement bench is as follows (Figure 11).

The black body (HGH RCN600) can generate infrared radiation emissions by fixing a temperature setting. Ambient temperature variations of the sensor are controlled by the temperature regulation system. The measured voltage output by the thermopile is then amplified using adapted instrumental electronics (high gain, common rejection, low offset temperature drift and low noise). Information is acquired by means of measurement and test instruments (acquisition card, voltmeters and oscilloscopes, etc.). Apart from automatic bench management, the acquisition card (PCI-6024E) enables interfacing of a computer to acquire and store measurement points. 


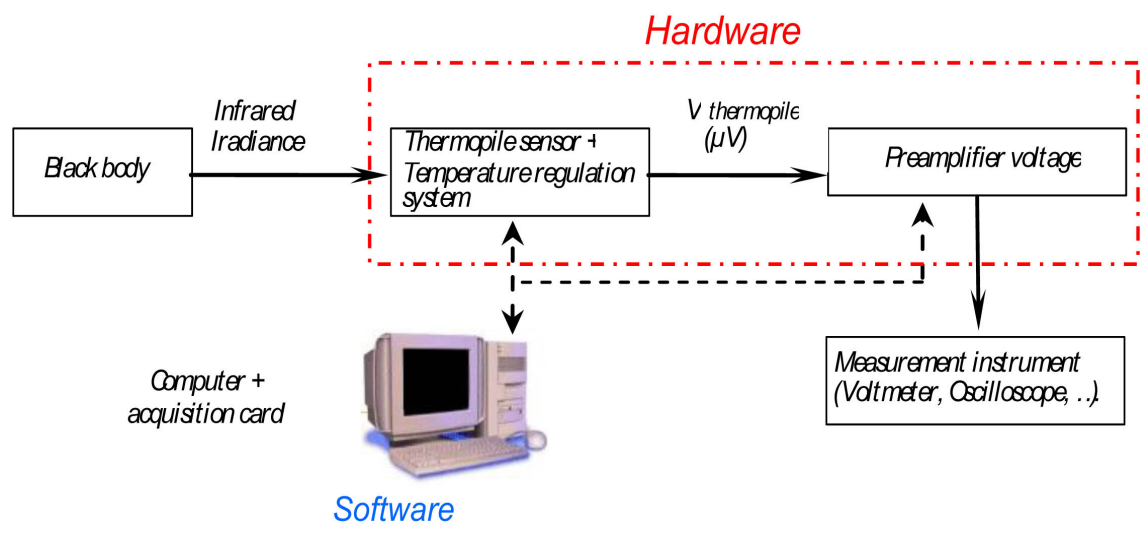

Figure 11. Characterization bench block diagram.

The temperature regulation system was designed so that it is possible to use it with a multifunction card controlled by a computer (automatic mode) or by an external control (manual and standalone mode). The choice of the element controlling the temperature variation is made on a Peltier effect thermoelectric cell (TEC). We added a temperature regulation to achieve optimum operation of the TEC (DT12-4). The temperature stabilization is based on the use of a PID corrector, a power amplifier $(60 \mathrm{~W})$ for control of the TEC, a type $\mathrm{K}$ thermocouple temperature measurement associated with a specific amplifier (AD595) and low noise operational amplifiers for the control (LT1124). The PID corrector is chosen so as to optimize the precision, stability and speed of the system $\left(M \varphi=45^{\circ}\right.$ et $\zeta=\sqrt{2} / 2$ ). To do this, the size of the corrector requires knowledge about the system to be slaved, in other words the equations have to be identified in the Laplace domain of the complete system. Furthermore, the Peltier effect cell and the power amplifier were allowed for in the identification method (Broïda method [26]). In doing so, we modeled the complete thermal system using high level simulation tools such as the Matlab-Simulink software. Thus, the designed thermal system can be used to configure the sensors within a temperature range varying from $-5^{\circ} \mathrm{C}$ to $+70^{\circ} \mathrm{C}$. Figure 11 and Figure 12 show a few experimental measurement examples to illustrate performances obtained by our systems. The average time response of the system with three successive temperature steps $\left(5^{\circ} \mathrm{C}, 10^{\circ} \mathrm{C}\right.$ and $\left.15^{\circ} \mathrm{C}\right)$ is obtained in about $15 \mathrm{~s}$ (Figure 12). For example, the temperature control system can maintain a constant temperature of $46^{\circ} \mathrm{C}$ with a static error measured at $\pm 0.05^{\circ} \mathrm{C}$ over a period of $11 \mathrm{~h}$ (Figure 13), over a long usage cycle.

Knowing that the thermopile is a DC voltage generator outputting a very low amplitude signal (a few hundred nanovolts to several millivolts) with a frequency range not exceeding about ten Hertz, this type of signal must be processed by an amplifier combining high gain and high impedance inputs. The noise and offset must also be reduced to not disturb the measured signal. Therefore the choice of components that contain the amplification system is of fundamental importance for this type of sensor. Since the circuit is designed to be inserted on the temperature regulation card, it is probable that it is affected slightly by 


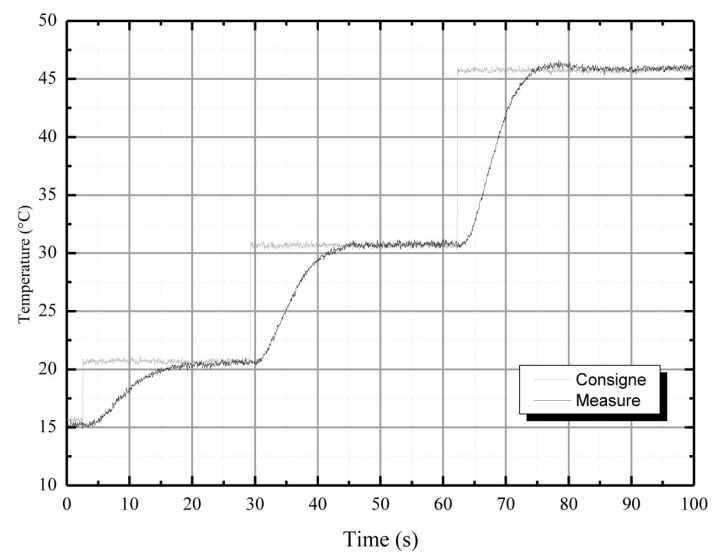

Figure 12. System response at different steps.

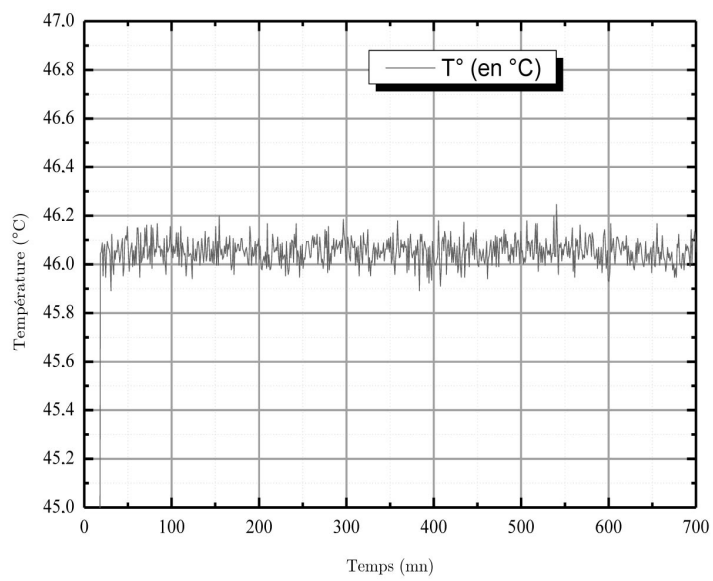

Figure 13. Temperature control stability as a function of time.

temperature variations, particularly generated by the TEC. This is why the electronic architecture of the amplifier is such that it disturbs the measurements as little as possible. Furthermore, note that the electronics designed for this assembly are very similar to the assembly used for the final presence detection module that must also have a low temperature drift to not distort detection.

The initially plan was to use a classical instrumentation amplifier with high gain and high CMRR. This type of component has a high performance differential amplification but has the disadvantage of the temperature drift of its offset ( 0.2 to $0.8 \mu \mathrm{V} /{ }^{\circ} \mathrm{C}$ ). This is why our choice has changed to chopper type amplifiers that have excellent performances for offset and temperature drifts. This amplifier range considerably reduces their own offset and noise level by a so-called auto-zero approach [27]. Thus, among components available on the market, operational amplifier AD8552 distributed by Analog Devices has been chosen for which the open loop gain is $130 \mathrm{~dB}$, the offset voltage is $1 \mu \mathrm{V}$, the offset drift is $0.005 \mu \mathrm{V} /{ }^{\circ} \mathrm{C}$ and the noise voltage is $40 \mathrm{nV} / \sqrt{\mathrm{Hz}}$. The power supply voltages and the potentials (power supply and reference voltages) are compensated for temperature by bandgap voltage reference circuits [28]. The total measured gain of the circuit is about $80 \mathrm{~dB}$. The output voltage acquired in a drying oven was 
used to measure the effect of temperature on the circuit. After amplification, it is found that the temperature drift of the circuit is $865 \mu \mathrm{V} /{ }^{\circ} \mathrm{C}$ over a temperature range between $25^{\circ} \mathrm{C}$ and $50^{\circ} \mathrm{C}$.

The measurement bench is automated using the LabVIEW software [29]. Different programs have been defined to perform temperature scans, constant temperature measurements and to adjust the offset. This enabled us to do a real time acquisition of the voltage output by the preamplification circuit, temperature and time. Finally, Figure 14 shows an overview of the regulation bench on which can be identified the temperature card, the preamplification card and the sensor housed in its machined aluminum support.

\subsection{Electrical Characterization}

\subsubsection{Evaluation of the Electrical Sensitivity}

Performances of infrared flux thermopile sensors are evaluated at constant temperature. The sensor is positioned a few centimeters away from the black body. The measurement bench keeps the sensor temperature constant in this situation. The power $P_{c}$ of the radiation flux collected by the thermopiles has to be known so that the sensitivity of structures can be determined. This is evaluated using the following equation [30]:

$$
P_{c}=\frac{1}{\pi} \varepsilon \int_{\lambda_{a}}^{\lambda_{b}} \frac{\partial(\mathrm{d} R / \mathrm{d} \lambda)}{\partial T}\left(\frac{\pi \Phi_{c n}^{2}}{4}\right) \frac{S_{c}}{d^{2}} \tau_{o p t}(\lambda) \mathrm{d} \lambda
$$

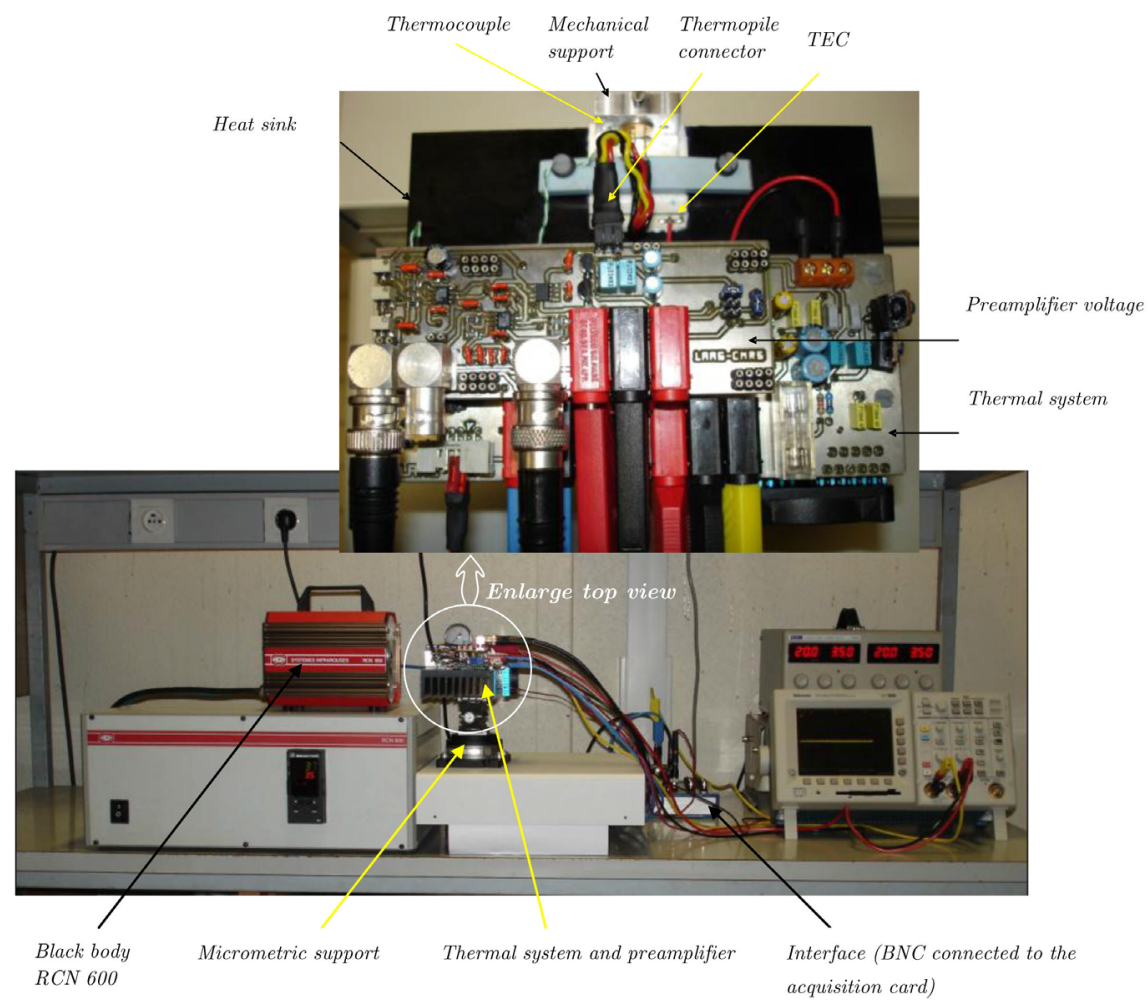

Figure 14. Overview of the temperature regulated measurement bench dedicated to characterization of thermopiles. 
We keep the temperature of the sensors at $25^{\circ} \mathrm{C}$ and we maintain the black body temperature at $75^{\circ} \mathrm{C}$. The distance between the black body and the sensor is fixed at $40 \mathrm{~mm}$. The ratio of the collected power (calculated in the $7-14 \mu \mathrm{m}$ spectral band) to the generated voltage gives the sensitivity (V/W), and depends on the aperture diameter of the black body $\left(F_{c n}=12.5 \mathrm{~mm}\right)$, the dimensions of the active zone of the structures $S_{c}$ (absorber area) and the coefficient of transmission of the infrared filter $t_{\text {opt }}$ The results given in Table 2 show that square structures $\left(C_{-} \times x\right)$ have a higher sensitivity $(63 \mathrm{~V} / \mathrm{W}$ and $82 \mathrm{~V} / \mathrm{W})$ than rectangular structures $\left(\mathrm{R}_{-} \times \mathrm{x}\right), 25 \mathrm{~V} / \mathrm{W}$ and $37 \mathrm{~V} / \mathrm{W}$. The sensitivities obtained are higher than values given in the literature and the electrical resistances are lower than those obtained usually [31] [32] [33] [34].

Since the two types of structures have the same number of thermocouples, square structures have significantly better sensitivities for the same arm length. As we demonstrated in our model, these results clearly show that oversizing the absorber affects the sensitivity of the sensors.

\subsubsection{Evaluation of the Electrical Sensitivity}

It is useful to evaluate the influence of the temperature drift of a sensor on its own performances, to satisfy the needs of our target application. It can be compensated by determining the equation for variation of the sensor. Compensation can then be achieved by a simple measurement of the sensor temperature. Therefore, we can use the measurement bench to configure the sensor temperature range. This is done by positioning the sensor a few centimeters from the black body $(40 \mathrm{~mm})$ and the temperature setting is $45^{\circ} \mathrm{C}$ to submit it to a constant radiation flow. We use the measurement bench to emulate an equation for variation of the internal temperature of the sensor. The temperature range is between $10^{\circ} \mathrm{C}$ and $45^{\circ} \mathrm{C}$ with a time between each measurement point equal to $1 \mathrm{mn}$. The black body has a temperature of $45^{\circ} \mathrm{C}$ and is $40 \mathrm{~mm}$ from the sensor. The results presented in Figures 15-18 show that the average drift of rectangular structures evaluated after amplification is $58 \mathrm{mV} /{ }^{\circ} \mathrm{C}$ for $400 \mu \mathrm{m}$ arms and 78 $\mathrm{mV} /{ }^{\circ} \mathrm{C}$ for $800 \mu \mathrm{m}$ arms. The average drift for square structures is evaluated at $52 \mathrm{mV} /{ }^{\circ} \mathrm{C}$ for $400 \mu \mathrm{m}$ arm and $75 \mathrm{mV} /{ }^{\circ} \mathrm{C}$ for $800 \mu \mathrm{m}$ arms.

These results show that the topology of the structures is not preponderant for the drift of sensors because the differences measured between square and

Table 2. Experimental measurements of the sensitivity and the resistance of few square thermopiles.

\begin{tabular}{cccccc}
\hline Structure & $\begin{array}{c}\text { Sensitivity } \\
(\mathrm{V} / \mathrm{W})\end{array}$ & $\begin{array}{c}\text { Resistance } \\
(\mathrm{k} \Omega)\end{array}$ & $\begin{array}{c}\text { Thermocouples } \\
(\mu \mathrm{m})\end{array}$ & $\begin{array}{c}\text { Absorber } \\
(\mu \mathrm{m})\end{array}$ & $\begin{array}{c}\text { Membrane } \\
(\mu \mathrm{m})\end{array}$ \\
\hline C_31 & 82 & 31 & 800 & $375 \times 375$ & $1400 \times 1400$ \\
C_21 & 63 & 15 & 400 & $325 \times 325$ & $1035 \times 1035$ \\
R_31 & 37 & 31 & 800 & $705 \times 280$ & $1305 \times 1385$ \\
R_21 & 25 & 15 & 400 & $600 \times 325$ & $1035 \times 0890$ \\
\hline
\end{tabular}




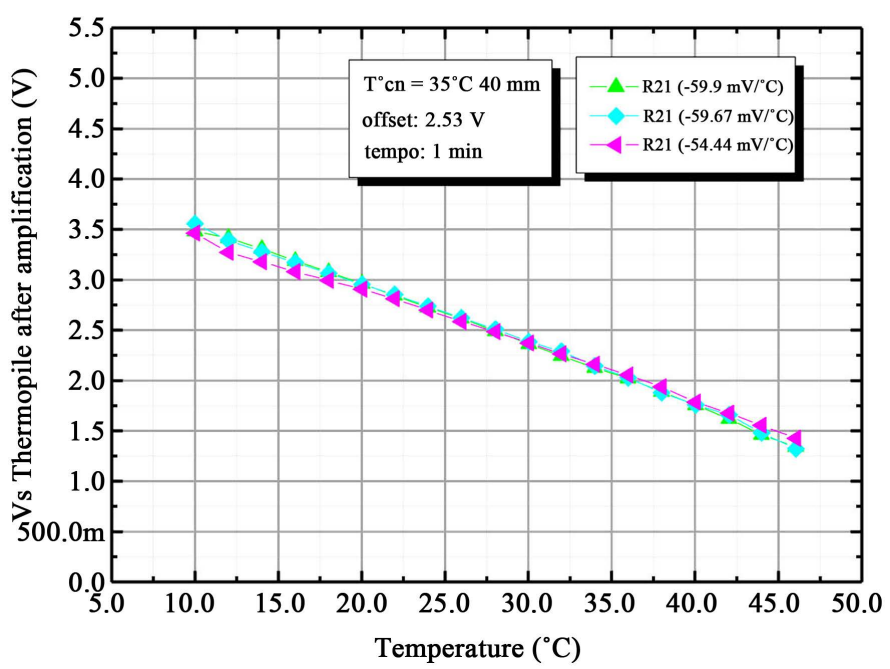

Figure 15. Temperature drift of rectangular type thermopiles ( $400 \mu \mathrm{m}$ arms).

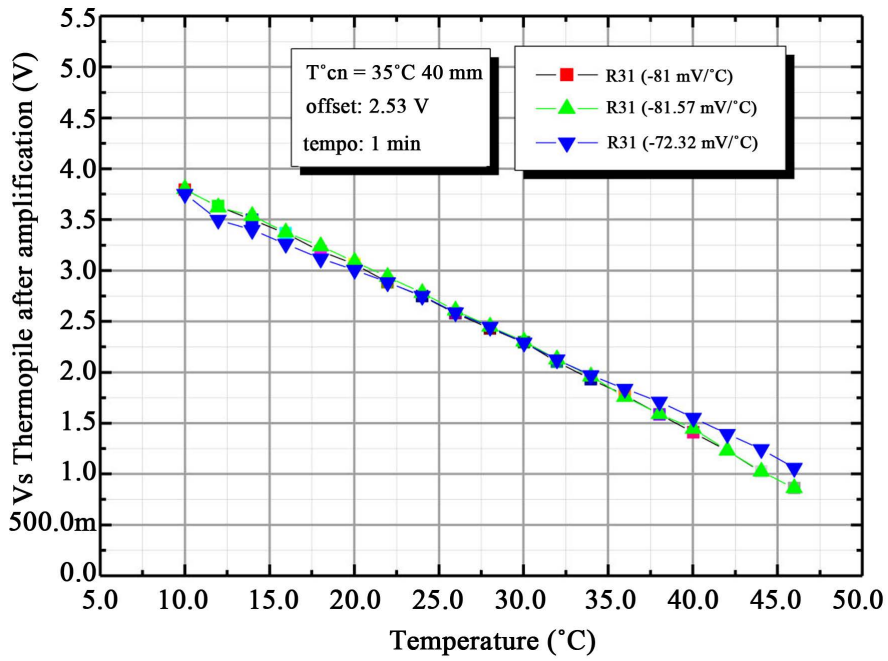

Figure 16. Temperature drift of rectangular type thermopiles ( $800 \mu \mathrm{m}$ arms).

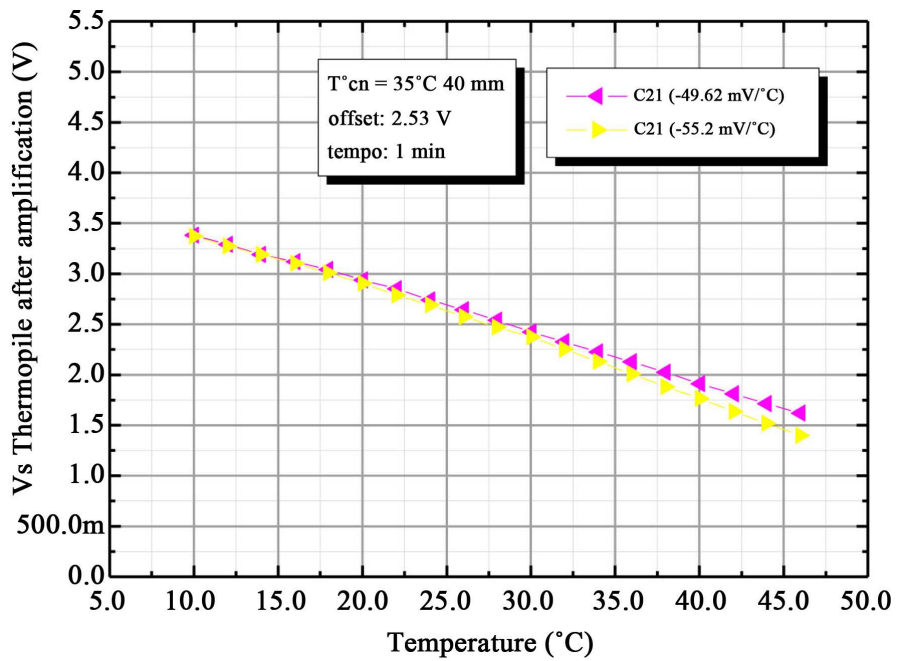

Figure 17. Temperature drift of square type thermopiles (400 $\mu \mathrm{m}$ arms). 


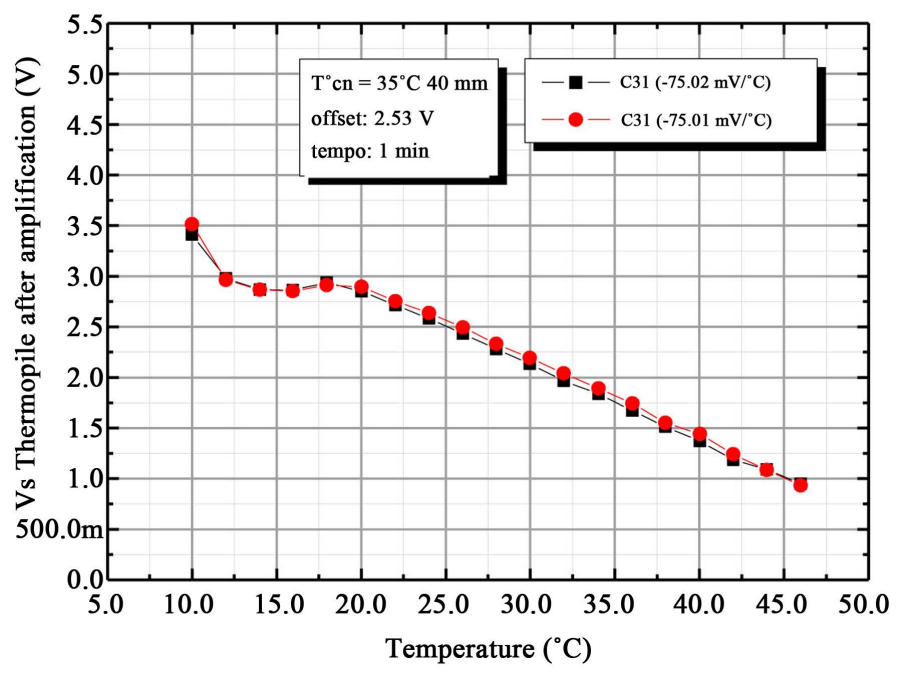

Figure 18. Temperature drift of square type thermopiles ( $800 \mu \mathrm{m}$ arms).

rectangular structures for the same length of thermocouple arms are relatively small. This clearly shows the importance of the choice of materials, particularly in terms of the temperature coefficient of resistance (TCR) and not the simple thermal conductivity. During the design of a thermopile, it may be better to choose materials with lower thermal conductivities and implicitly a lower merit factor, but that minimizes the temperature drift of a sensor. It is then preferable to choose materials with a low TCR to achieve a better thermal stability of sensors.

\subsubsection{Evaluation of the NETD}

The measurement method is based on acquisition of the response of the sensor when it is subjected to two different homogenous temperature fluxes $T_{1}$ and $T_{2}$. Under the action of fluxes generated with a black body, the sensor outputs two consecutive voltages $V_{T 1}$ and $V_{T 2}$ at the temperature change [35]. The noise equivalent temperature difference (NETD) is evaluated using the following equation:

$$
\mathrm{NETD}=\frac{\left\langle V_{n}\right\rangle}{\frac{\partial V}{\partial T}}
$$

with:

$$
\frac{\partial V}{\partial T}=\frac{V_{T 2}-V_{T 1}}{T_{2}-T_{1}}
$$

The term $\partial V / \partial T$ represents the thermal sensitivity of the detector $(\mathrm{V} / \mathrm{K})$ where $\left\langle V_{n}\right\rangle$ is the RMS noise voltage output from the sensor and the electronics of the preamplification circuit that we have described. Table 3 shows the experimental evaluation of the NETD for a few square and rectangular shaped thermopiles. Overall, we observe that the NETD of the thermopiles realized are between $222 \mathrm{mK}$ and $395 \mathrm{mK}$. The results are significant. Structures with thermocouple arm lengths of $800 \mu \mathrm{m}$ have a better quality NETD. 
Table 3. Experimental evaluation of NETD for a few squareand rectangular thermopiles.

\begin{tabular}{cccc}
\hline Structure & $\left\langle V_{n}\right\rangle$ & $\partial V / \partial T$ & NETD \\
\hline C_31 & $3.38 \mathrm{mV}$ & $16.25 \mathrm{mV} / \mathrm{K}$ & $208 \mathrm{mK}$ \\
C_21 & $3.86 \mathrm{mV}$ & $11.32 \mathrm{mV} / \mathrm{K}$ & $340 \mathrm{mK}$ \\
R_31 & $2.82 \mathrm{mV}$ & $12.70 \mathrm{mV} / \mathrm{K}$ & $222 \mathrm{mK}$ \\
R_21 & $2.65 \mathrm{mV}$ & $07.15 \mathrm{mV} / \mathrm{K}$ & $370 \mathrm{mK}$ \\
\hline
\end{tabular}

\section{Conclusion}

It is found that a thermopile has definite advantages over a bolometer for the development of a static presence detection system for smart home applications (no $1 / \mathrm{f}$ noise, linear response, self-generator, etc.). This work has enabled us to set up a methodology for modeling the temperature distribution along the structure by means of equations. We have presented its main characteristics in the form of analytic equations, to provide an aid to sizing of adapted structures. We then presented all CMOS compatible technological steps necessary for manufacturing of the sensors. We designed and made a specific measurement bench and used it to evaluate performances in terms of electrical sensitivities, temperature drifts and NETD drifts, to characterize the different manufactured structures. Compared with the results in Table 3, it was found that the structures with optimal performances ( $\mathfrak{R}_{v}=82 \mathrm{~V} / \mathrm{W}, \mathrm{R}=31 \mathrm{k} \Omega$, NETD $\left.=208 \mathrm{mK}\right)$ are square in shape and have longer thermocouples $(800 \mu \mathrm{m})$. We are now continuing this work, concentrating on two topics. Firstly, we are studying the potential physical influence of the contact surface between two component materials of a thermocouple on the global thermoelectric capacity of a thermopile. At the same time, we are developing wireless type electronics so as to integrate the matrix thermopiles produced into Wireless Sensor Network dedicated to smart home applications.

\section{Acknowledgements}

The authors thank the staff of the microfabrication laboratory of LAAS-CNRS (Techniques and Equipment Applied to Microelectronics) for their assistance in the fabrication process.

\section{Conflicts of Interest}

The authors declare no conflicts of interest regarding the publication of this paper.

\section{References}

[1] Farhad, F., Ehsan, J. and Seyed Jalil, Y. (2016) Fabrication and Characterization of Fast Response Pyroelectric Sensors Based on Fe-Doped PZT Thin Films. Journal of Materials Science-Materials in Electronics, 27, 6578-6585.

https://doi.org/10.1007/s10854-016-4603-5 
[2] Cao, L.-M., Zhang, Y.-Z., Sun, S.-J., Guo, H. and Zhang, Z. (2008) Structure Design and Test of MEMS Thermocouple Infrared Detector. Microsystem Technologies Micro and Nanosystems Information Storage and Processing Systems, 24, 2463-2471.

[3] Boutchich, M., Ziouche, K., Ait-Hammouda Yala, M., Godts, P. and Leclercq, D. (2005) Package-Free Infrared Micro Sensor Using Polysilicon Thermopile. Sensors and Actuators A, 121, 52-58. https://doi.org/10.1016/j.sna.2005.01.016

[4] Wang, H., Yi, X. and Chen, S. (2006) Low Temperature Fabrication of Vanadium Oxide Films for Uncooled Bolometric Detectors. Infrared Physics \& Technology, 47, 273-277. https://doi.org/10.1016/j.infrared.2005.04.001

[5] Lim, S., Choi, J., Horowitz, R. and Majumdar, A. (2005) Design and Fabrication of a Novel Bimorph Micro-Optomechanical Sensor. Journal of Microelectromechanical Systems, 14, 683-690. https://doi.org/10.1109/JMEMS.2005.845446

[6] Xu, D.H., Wang, Y.L., Xiong, B. and Li, T. (2017) MEMS-Based Thermoelectric Infrared Sensors: A Review. Frontiers of Mechanical Engineering, 12, 557-566. https://doi.org/10.1007/s11465-017-0441-2

[7] Li, Y., Zhou, H., Li, T., Wang, Y., Liu, Y. and Wang, Y. (2010) CMOS-Compatible 8 $\times 2$ Thermopile Array. Sensors and Actuators A, 161, 120-126. https://doi.org/10.1016/j.sna.2010.04.026

[8] Jan, P., Roman, P., Vojtech, S., et al. (2017) Self-Compensating Method for Bolometer-Based IR Focal Plane Arrays. Sensors and Actuators A, 265, 40-46. https://doi.org/10.1016/j.sna.2017.08.025

[9] Qian, X., Xu, Y.P. and Karunasiri, G. (2004) Self-Heating Cancellation Circuits for Microbolometer. Sensors and Actuators, A111, 196-202. https://doi.org/10.1016/j.sna.2003.10.035

[10] Premachandran, C.S., Chong, S.C., Chai, T.C. and Iyer, M. (2004) Vacuum Packaging Development and Testing for an Uncooled IR Bolometer Device. 54th Electronic Components and Technology Conference, Las Vegas, NV, 4 June 2004, 951-955.

[11] Fisette, B., Tremblay, M., Oulachgaret, H., et al. (2017) Novel Vacuum Packaged 384 x 288 Broadband Bolometer FPA with Enhanced Absorption in the 3-14 mu m Wavelength Range. Conference on Infrared Technology and Applications, Anaheim, February 2017, 101771R-10177-15.

[12] Socher, E., Bochobza-Degani, O. and Nemirovsky, Y. (2001) A Novel Spiral CMOS Compatible Micromachined Thermoelectric IR Microsensor. Journal of Micromechanics and Microengineering, 11, 574-576. https://doi.org/10.1088/0960-1317/11/5/320

[13] Hsun, C. and Cheng, K. (1999) Optimization Criteria of CMOS Compatible Thermopile Sensors. Proceedings of SPIE, 8 October 1999, 116-126.

[14] Kou, S. and Akai, H. (2018) First-Principles Calculation of Transition-Metal Seebeck Coefficients. Solid State Communications, 276, 1-4. https://doi.org/10.1016/j.ssc.2018.02.018

[15] Völklein, F. and Baltes, H. (1992) Thermoelectric Properties of Polysilicon Films Doped with Phosphorus and Boron. Sensors and Materials, 3, 325-334.

[16] Escriba, C., Campo, E., Estève, D. and Fourniols, J.Y. (2005) Complete Analytical Modeling and Analysis of Micromachined Thermoelectric Uncooled IR Sensors. Sensors and Actuators A, 120, 267-276. https://doi.org/10.1016/j.sna.2004.11.027

[17] Elbel, T., Lenggenhager, R. and Baltes, H. (1992) Model of Thermoelectric Radiation Sensors Made by CMOS and Micromachining. Sensors and Actuators A, 35, 
101-106. https://doi.org/10.1016/0924-4247(92)80147-U

[18] Volklein, F. and Baltes, H. (1993) Optimization Tool for the Performance Parameters of Thermoelectric Microsensors. Sensors and Actuators A, 36, 65-71. https://doi.org/10.1016/0924-4247(93)80142-4

[19] Dillner, U. (1994) Thermal Modeling of Multilayer Membranes for Sensor Applications. Sensors and Actuators A, 41, 260-267. https://doi.org/10.1016/0924-4247(94)80121-5

[20] Xu, D., Xiong, B. and Wang, Y. (2010) Modeling of Front-Etched Micromachined Thermopile IR Detector by CMOS Technology. Journal of Microelectromechanical Systems, 19, 1331-1340.

[21] Gaiseanu, F., Tsoukalas, D., Esteve, J., Postolache, C., Goustouridis, D. and Tsoi, E. (1997) Chemical Etching Control during the Self-Limitation Process by Boron Diffusion in Silicon: Analytical Results. International Semiconductor Conference 20 th Edition, Sinaia, 7-11 October 1997, 247-250.

[22] Rossi, C., Scheid, E. and Estève, D. (1997) Theoretical and Experimental Study of Silicon Micro Machined Micro Heater with Dielectric Stacked Membranes. Sensors and Actuators A, 63, 183-189. https://doi.org/10.1016/S0924-4247(97)80503-1

[23] Temple Boyer, P., Rossi, C., Saint Etienne, E. and Scheid, E. (1998) Residual Stress in Low Pressure Chemical Vaport Deposition $\operatorname{SiN}_{\mathrm{x}}$ Films Deposited from Silane and Ammonia. Journal of Vacuum Science \& Technology, 16, 2003-2337. https://doi.org/10.1116/1.581302

[24] Rossi, C., Temple Boyer, P. and Estève, D. (1998) Realization and Performance of Thin $\mathrm{SiO}_{2} / \mathrm{SiN}_{\mathrm{x}}$ Membrane for Microheater Applications. Sensors and Actuators A, 64, 241-245. https://doi.org/10.1016/S0924-4247(97)01627-0

[25] Iosub, R., Moldovan, C. and Modreanu, M. (2002) Silicon Membranes Fabrication by Wet Anisotropic Etching. Sensors and Actuators A, 99, 104-111. https://doi.org/10.1016/S0924-4247(01)00906-2

[26] Bitter, R., Mohiuddin, T. and Nawrocki, M.R. (2006) LabVIEW: Advanced Programming Techniques. CRC Press, Boca Raton, 499.

[27] Kusuda, Y. (2015) A 60 V Auto-Zero and Chopper Operational Amplifier with 800 $\mathrm{kHz}$ Interleaved Clocks and Input Bias Current Trimming. Journal of Solid State Circuits, 50, 2804-2813. https://doi.org/10.1109/JSSC.2015.2456891

[28] Souliotis, G., Plessas, F. and Vlassis, S. (2018) A High Accuracy Voltage Reference Generator. Microelectronics Journal, 75, 61-67.

[29] Chacon, J., Vargas, H., Farias, G., et al. (2015) EJS, JIL Server, and LabVIEW: Architecture for Rapid Development of Remote Labs. IEEE Transactions on Learning Technologies, 8, 393-401. https://doi.org/10.1109/TLT.2015.2389245

[30] Gaussorgues, G. (1999) La Thermographie Infrarouge: Principes, Technologies, Applications. Tech. \& Doc./Lavoisier.

[31] Shen, C.-H. and Wang, B.-W. (2004) A High Performance CMOS Compatible Thermopile Based on Noise Added Mechanism. Sensors, Vienna, 24-27 October 2004, 611-614.

[32] Liu, Y., Shen, D. and Zhu, Z. (2002) The Design of Adding Heat Reflective Emitter Coating on the Cold Region of Infrared Thermopiles. 21 st International Conference on Thermoelectrics, Long Beach, 29 August 2002, Vol. 21, 458-462.

[33] Schaufelbühl, A., et al. (2001) Uncooled Low-Cost Thermal Infrared Based on Micromachined CMOS Integrated Sensor Array. Journal of Micromechanics and Microengineering, 10, 503-510. 
[34] Akin, T., Olgun, Z., Akar, O. and Kulah, H. (1998) An Integrated Thermopile Structure with High Responsivity Using Any Standard CMOS Process. Sensors and Actuators A, 66, 218-224. https://doi.org/10.1016/S0924-4247(98)00038-7

[35] Pajani, D. (1989) Mesure par thermographie infrarouge. ADD Editeur. 